\title{
ANÁlise de CITAÇões EM TEXTOS ACADÊMICOS ESCRITOS*
}

\author{
(An analysis of citations in written academic texts)
}

\author{
Tatiana S. de Macedo (UFPA) \\ Adriana Silvina PAGANO (UFMG)
}

\begin{abstract}
This article reports on a study of citations in academic writing from the perspective of citation analysis and genre analysis (Moravcsik \& Murugesan, 1975; Swales, 1986, 1990, 2004; Bhatia, 2004). The study focuses on the use of citations by expert and novice members of the Linguistics community and presents a comparative analysis of nine research articles and thirteen student term papers in that area. The results show that the linguistic choices that guide the writing of citations are largely shared by the expert members (authors of the research articles) and the novice ones (graduate students authoring the papers) in that both tend to choose confirmative over negative citations. Unlike novices, however, expert members tend to use their own voices to confront other authors. The implications of this study reinforce the need for Language Teaching Education Programs to offer a genre-based approach to discourse aimed at developing students' rhetorical consciousness about academic writing, and consequently about the use of citations in written texts, thereby enabling novices to build up an authorial positioning within their discourse community.

Key-words: academic writing; genre; citation analysis.
\end{abstract}

Resumo: Este artigo apresenta um estudo de citações em escrita acadêmica na perspectiva da análise de citaçoes e dos estudos de gêneros do discurso (Moravcsik \& Murugesan, 1975; Swales, 1986, 1990, 2004; Bhatia, 2004). O estudo enfoca o uso de citações por membros expertos e membros novatos da comunidade acadêmica de Linguística e consistiu na análise e comparação de nove artigos acadêmicos e treze trabalhos finais de disciplina. Os resultados mostram que as escolhas linguísticas que orientam a escrita das citaçöes são em grande parte compartilhadas pelos membros expertos (autores dos artigos acadêmicos) e pelos novatos (alunos de curso de pós-graduação, autores dos trabalhos finais de disciplina), haja vista que ambos fazem uso de citaçôes confirmativas, em detrimento de negativas. Todavia, membros expertos, ao contrário dos novatos, utilizam a própria voz para confrontar outros autores. As implicaçôes deste estudo reiteram a necessidade de os Cursos de Letras terem uma

* Agradecemos à Profa. Msc. Sonia Celia Faria de Oliveira e à Profa. Msc. Cristina Vasconcelos Porto, da Universidade Federal do Pará (UFPA), por suas valiosas contribuições a este trabalho.

D.E.L.T.A., 27:2, 2011 (257-288) 
abordagem de ensino e aprendizagem de escrita acadêmica baseada em gêneros do discurso visando desenvolver a consciência retórica dos alunos em relação à escrita acadêmica e, consequentemente, ao uso de citações em textos escritos, de maneira a empoderar os alunos a construir um posicionamento autoral em sua comunidade discursiva.

Palavras-chave: escrita acadêmica; gêneros do discurso; análise de citações.

\section{INTRODUÇÃO}

Constitui pressuposto das abordagens de escrita acadêmica orientadas para a formação e empoderamento do aluno universitário, a expectativa de que, ao estudar criticamente a função social e a organização retórica dos gêneros do discurso que são utilizados como mecanismos de comunicação em sua comunidade discursiva - no caso, a comunidade acadêmica -, o aluno pode aprimorar a produção de seus próprios textos tendo, assim, a oportunidade de fazer-se ouvir nessa comunidade. Esse processo de apropriação dos gêneros do discurso pode ocorrer na medida em que o ensino e a aprendizagem mostrarem-se úteis para atender aos interesses e necessidades do aluno.

No Brasil as pesquisas sobre a escrita acadêmica em cursos de pósgraduação são ainda incipientes. Estudos que enfoquem essa realidade são necessários, pois podem resultar em uma maior compreensão de aspectos do ensino e da aprendizagem nesses cursos, como a construção de textos acadêmicos escritos, foco desta pesquisa.

Este artigo descreve parte dos resultados apresentados na tese de doutorado sobre citações em textos acadêmicos escritos intitulada "A citação como recurso de afiliação acadêmica" (Macedo, 2006), orientada pela Profa. Dra. Adriana Pagano. A decisão de analisar as práticas de citação em exemplares de gêneros do discurso característicos da área de Letras justifica-se pela intenção de se observar o modo como a construção do discurso da comunidade acadêmica estabelece parâmetros para a produção de textos escritos por alunos de pós-graduação. Assim, consideramos pertinente observar os meios pelos quais o aluno incorpora ao seu próprio repertório estruturas retóricas de sua comunidade discursiva - enfocando, especificamente, o uso de citações, que são elementos presentes em diversos gêneros do discurso característicos dessa comunidade. Como parâmetro de comparação utilizamos artigos acadêmicos já publicados a fim de observar se o uso das citações 
em textos produzidos por membros expertos ${ }^{1}$ da comunidade acadêmica poderia ser correlacionado com a produção de textos de membros novatos (no caso desta pesquisa, alunos de pós-graduação).

Além desta Introdução, o presente artigo está constituído pelas seguintes seções: a Revisão da Literatura, dividida em quatro tópicos, nos quais são abordadas questões relacionadas aos gêneros do discurso em suas relações com o conhecimento experto, ao artigo acadêmico e à estrutura das citações; a Metodologia, na qual os participantes, os dois corpora analisados e os procedimentos de análise são apresentados; a seção de Análise de Dados e Resultados, que apresenta a análise realizada e os padrões encontrados; e, por último, a seção de Discussão e Considerações Finais, seção na qual refletimos sobre os resultados desta pesquisa no escopo dos estudos existentes conforme nossa revisão teórica.

\section{O GÊNERO DO DISCURSO E O DESENVOLVIMENTO DO CONHECIMENTO EXPERTO PROFISSIONAL}

A escrita é um processo social em que todos os mecanismos utilizados para a construção do texto contribuem para engajar os leitores do pesquisador-autor em seu discurso, em um esforço de persuadi-los sobre a relevância do conteúdo do texto (Hyland, 1999).

Gênero do discurso e discurso entrelaçam-se na construção da identidade do autor. Os gêneros são definidos por propósitos, papéis e relações sociais estabelecidos por determinado grupo social, enquanto que o discurso é definido por questões ideológicas que envolvem história, engajamento em causas sociais, profissionais etc. (Ivanič, 1998).

As escolhas linguísticas e retóricas do autor de um dado texto vão associá-lo a determinada linha de pensamento. Segundo Ivanič (1998), o autor do artigo acadêmico precisa, por exemplo, decidir em que momento do texto fazer uma citação e precisa estar ciente de que, por meio de suas citações e da forma como elas são construídas, explicita sua afiliação a va-

1. Bhatia (2004) define como experto o profissional especialista em uma área de estudos que, ao ter conhecimento aprofundado sobre o sistema de gêneros do discurso que sua comunidade discursiva utiliza para comunicação entre seus membros, consegue apropriar-se desses gêneros em suas atividades profissionais diárias. 
lores e tradições de um determinado grupo social. Algumas características do discurso são definidas por esses valores e tradições, marcando, assim, a inserção do autor do artigo em um determinado grupo social.

Para Ivanič, o aluno, muitas vezes, tem um sentimento ambivalente em relação às convenções da escrita acadêmica: segue-as, não por concordar com elas, mas para ter seus trabalhos acadêmicos aceitos pela academia e pelo professor da disciplina. Muitas vezes, o aluno é pressionado a "adotar uma voz que ainda não possui” (Ivanič, 1998:86). Por essa razão, o aluno debate-se ante sentimentos de acomodação e de resistência, procurando construir sua própria identidade ${ }^{2}$, ao mesmo tempo em que busca pertencer à comunidade acadêmica, acatando suas convenções.

Conforme explicita Ivanič (1998), as características do discurso acadêmico são definidas tanto pelos valores, interesses e práticas da comunidade acadêmica quanto pelas características de cada área de estudo, curso, disciplina e, mesmo, instituições de ensino aos quais os cursos estejam ligados. Pautar-se pelas regras de construção de um trabalho acadêmico pode não posicionar o escritor em sua comunidade acadêmica, mas auxilia-o nesse posicionamento. A questão é que realizar um trabalho com o objetivo de ser avaliado por um professor posiciona o escritor como aluno, e não como um contribuinte para sua área de estudo. Para Ivanič (1998), essa é uma das diferenças marcantes entre o trabalho acadêmico (no caso desta pesquisa, o trabalho final de disciplina) e o artigo acadêmico, uma vez que o propósito social do artigo acadêmico é o de contribuir para a área de conhecimento na qual o autor está inserido.

Mustafa (1995) considera o trabalho final de disciplina um gênero do discurso por ser baseado em questionamentos e levantamento teórico destinados a veicular informações em uma dada comunidade discursiva segundo regras e convenções linguísticas, retóricas, acadêmicas e profissionais. Para o referido autor, esse é um gênero que deve ser estudado pelo aluno de graduação para que venha a ter conhecimento das convenções envolvidas na construção do trabalho final e para que, no futuro, possa aplicá-las, adaptando-as segundo as especificidades da área de estudo na qual esse aluno decidir desenvolver seus trabalhos de pesquisa.

2. Ivanič (1998) defende que o que define nossa identidade são os interesses, valores e crenças construídos ao longo de nossa história no âmbito de nossa etnia, classe social, profissão, idade etc. 
Bhatia (2004) considera a escrita profissional (que ele opõe àquela dos trabalhos acadêmicos desenvolvidos por alunos para disciplinas na academia, os quais são escritos, geralmente, para fazerem parte da Avaliação de Curso dos alunos) uma escrita complexa, dinâmica e multifuncional, uma vez que é construída pelo entrelaçamento de discursos diversos. Seguindo essa linha de pensamento, Ivanič (1998) observa que o discurso acadêmico é um espaço de conflitos entre ideologias diferentes e onde as relações de poder estão em constante tensão. É um espaço em que aquele que escreve tem que gerenciar múltiplas identidades: a de pesquisador, a de autor, e a de membro de, às vezes, mais de uma comunidade discursiva. Além disso, em um mesmo texto, o autor, não poucas vezes, precisa lidar com múltiplas identidades, uma vez que, dependendo da seção do texto que esteja redigindo, poderá ter que se posicionar de maneira diferente - com maior ou menor envolvimento pessoal, por exemplo. Aspectos da relação do membro da comunidade discursiva com os gêneros do discurso utilizados por essa comunidade serão vistos a seguir.

\section{O MEMBRO EXPERTO DA COMUNIDADE DISCURSIVA ${ }^{3}$ E A SUA}

\section{RELAÇÃO COM OS GÊNEROS DO DISCURSO}

Segundo Pueyo (2001), fazer ciência é tentar entender o mundo por meio de um processo que transforme reflexões sobre um dado objeto de estudo em conhecimento científico. Conforme observado pela autora, nesse processo os membros da comunidade acadêmica constroem seus textos de modo a utilizar "uma série de recursos léxico-gramaticais para construir o seu campo de conhecimento" (Pueyo, ibid:192). Swales (1990) defende que, uma vez que os membros de uma dada comunidade discursiva utilizam gêneros do discurso como mecanismos de intercomunicação, é necessário que se ative e desenvolva a capacidade de reconhecer em seus textos a organização retórica que os afilia a determinados gêneros do discurso, bem como os propósitos desse gênero em relação à comunidade discursiva com a qual constituirá um vínculo. É preciso, portanto, que seja desenvolvida a consciência retórica (Swales, 1990:13) dos alunos.

3. Swales (1990, 1998) define comunidade discursiva como um grupo de pessoas que utilizam mecanismos de comunicação específicos e que possuem alguns objetivos em comum. Ainda segundo o autor, essa comunidade caracteriza-se pela utilização de gêneros do discurso e de léxico específicos, e pela presença de membros com considerável conhecimento experto profissional. 
Os textos científicos das sociedades ocidentais não apresentam características específicas por acaso; essas características "estão ligadas a um construto social sobre ciência, o qual possui ramificações ideológicas, tecnológicas, econômicas e políticas" (Kress, 1994:125). Para Kress, possibilitar ao aluno o acesso ao conhecimento desse construto significa reconhecer o potencial ideológico e social que o ensino e aprendizagem de gêneros do discurso possuem. Assim, é possível concluir que o discurso profissional daqueles que trabalham com o ensino e a aprendizagem de línguas tem o duplo papel de mostrar ao futuro professor uma forma de ser, e de prover ferramentas que viabilizarão a reflexão sobre sua realidade específica (Murray, 1998).

Segundo Bhatia (2004:114), os membros expertos da comunidade discursiva "identificam, constroem, interpretam, usam e exploram construções genéricas de uma maneira que seja socialmente aceitável" pelos demais membros da comunidade. Mesmo que ocorram algumas variações nas convenções que regem a organização dos diversos gêneros do discurso que a comunidade elegeu para veicular informações, há características que se mantém estáveis propiciando uma certa integridade ao gênero. É isso que permite que os membros da comunidade reconheçam os gêneros por meio dos quais a comunicação ocorrerá. Para o autor, essa integridade genérica é percebida na medida em que os gêneros apresentam uma prototipicidade por estarem relacionados a uma "constelação de correlações de forma e função socialmente construída, representante de um construto de comunicação típico de um dado grupo profissional, acadêmico ou institucional" (Bhatia, 2004:123). O autor observa, no entanto, que há espaço para a criatividade, pois a combinação dos elementos que fazem parte dos gêneros não é estática nem inflexível.

Para Bhatia (2004), há indicadores intratextuais (text-internal) e extratextuais (text-external) da integridade genérica. Os indicadores intratextuais, que se referem a aspectos relacionados à construção e interpretação dos textos, são os seguintes: a) contextuais, que abrangem o propósito e o contexto comunicativo; b) textuais, que compreendem os recursos léxicos, retórico-gramaticais e discursivos usados para construir o texto; c) intertextuais, que estão relacionados ao número de vozes presentes no texto. Os indicadores extratextuais referem-se ao contexto sociocultural da comunidade disciplinar que utilizará e interpretará os textos e consistem em: a) práticas discursivas, que incluem fatores como a escolha do gênero 
que mediará a comunicação; b) procedimentos discursivos, que estruturam a construção do gênero na medida em que determinam, por exemplo, em que estágio e por meio de quais mecanismos algo/alguém contribuirá para a construção do referido gênero; c) cultura disciplinar (disciplinary culture), que define não apenas os objetivos, as normas e convenções dos gêneros utilizados pela comunidade, mas também a natureza e a identidade do profissional que busca pertencer a essa comunidade.

Bhatia (2004) afirma que os conceitos de integridade genérica, competência genérica e conhecimento experto profissional estão intimamente relacionados. Podemos entender essa relação da seguinte forma: para que o profissional possa apropriar-se de um dado gênero do discurso é preciso que tenha conhecimento de como esse gênero funciona em sua comunidade discursiva, ou seja, os propósitos comunicativos que dão origem a esse gênero, as convenções e normas que ditam suas características retóricas e léxico-gramaticais, o nível de flexibilidade que essas normas e convenções podem apresentar e as relações sociais que são intermediadas por esse gênero. Esse conhecimento, que é construído na medida em que o profissional interage em sua comunidade discursiva, permitirá que novos exemplares do gênero sejam produzidos, exemplares esses que poderão apresentar algumas inovações, mesmo guardando características prototípicas do gênero.

Bhatia (2004) apresenta o seguinte diagrama para ilustrar a sua idéia de conhecimento experto profissional, aqui traduzido por nós:

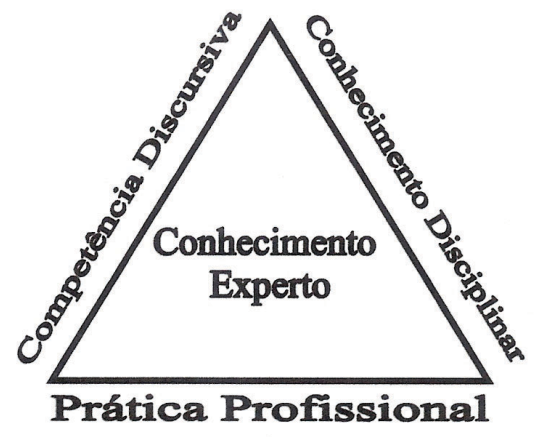

Figura 1: Especificação do conhecimento experto profissional.

Fonte: Bhatia $(2004: 146)^{4}$.

4. No diagrama original: "Professional expertise: professional practice; disciplinary knowledge; discursive competence” (Bhatia, 2004:146). 
De acordo com Bhatia, a competência discursiva envolve a competência textual, a genérica e a social. A competência textual compreende a habilidade de lidar com a linguagem e de utilizar o conhecimento textual, contextual e pragmático para estruturar, organizar e interpretar textos associados a diversos gêneros. A competência genérica relaciona-se à "habilidade de identificar, construir, interpretar e explorar com sucesso o repertório de gêneros" (Bhatia, 2004:144). A competência social envolve a habilidade de utilizar a linguagem para interagir em diversos contextos sociais e institucionais. $\mathrm{O}$ autor explica, ainda, que há várias maneiras de se alcançar um nível de conhecimento experto profissional que venha caracterizar o indivíduo como membro experto da comunidade discursiva. Em diferentes momentos da carreira, em diferentes níveis e maneiras, o conhecimento experto poderá ser construído por meio do desenvolvimento do conhecimento disciplinar, relacionado à experiência em áreas de estudo específicas e da prática profissional advinda de treinamento profissional e da aprendizagem no próprio local de trabalho, ao longo dos anos.

Sendo as competências textual e genérica fatores importantes no desenvolvimento do conhecimento experto profissional, é interessante observar como membros novatos e membros expertos da comunidade acadêmica lidam com gêneros característicos dessa comunidade. Um deles, o artigo acadêmico, será discutido a seguir.

\section{O GÊNERO ARTIGO ACADÊMICO}

Os gêneros do discurso acadêmico, na visão de Swales (1993), relacionam-se uns aos outros de forma simbiótica, uma vez que, não raramente, alimentam-se de características mútuas, formando um Sistema de Gêneros. O autor observa que os gêneros do discurso que fazem parte do referido sistema parecem competir entre si pelas atenções da comunidade acadêmica em um estado de tensão dinâmica. Esses gêneros são os mecanismos que a comunidade decidiu legitimar como forma de estabelecer o diálogo entre seus membros.

O artigo acadêmico possui uma relação dinâmica com outros gêneros de pesquisa, como os abstracts, teses, dissertações e apresentações orais. Swales (1990) define o artigo acadêmico como um texto escrito, não muito longo, que apresenta o relato de uma pesquisa e que é veiculado em periódicos especializados e, algumas vezes, em coletâneas organizadas em livros. $\mathrm{O}$ 
artigo geralmente procura relacionar os achados da pesquisa relatada com trabalhos já realizados na área de estudo, bem como procura discutir questões ligadas à teoria e/ou à metodologia. Sob a perspectiva dos estudos da escrita, Ivanič (1998) observa que o objetivo do artigo acadêmico é o de contribuir para a construção do conhecimento.

\subsection{A organização retórica do artigo acadêmico}

De acordo com Hill et al. (1982 apud Motta-Roth, 2001), o artigo acadêmico, de modo geral, apresenta as seguintes seções: Introdução, Métodos, Resultados, Discussão e Conclusão. Swales e Feak (1994) apontam os objetivos das diversas seções: a Introdução a um só tempo estabelece o tema do artigo, revê a literatura e procura atrair a atenção do leitor para o artigo; a seção de Métodos - a mais sucinta do artigo acadêmico - descreve a metodologia, os materiais e os procedimentos da pesquisa; a seção de Resultados descreve e comenta os achados; a seção de Discussão explicita o que foi aprendido com a pesquisa, partindo de generalizações sobre os achados. Motta-Roth e Hendges consideram que a Revisão da Literatura tem, entre outras funções, a de "utilizar, reconhecer e dar crédito à criação intelectual de outra(os) autoras(es)" (2010:90). Swales (2004) explica que a Revisão da Literatura, em artigos acadêmicos, pode apresentar-se de três formas diferentes: a) pode ser uma seção independente, a 'Revisão da Literatura' (grifo do autor); b) pode ser incorporada ao texto maior que compõe o artigo; c) pode estar diluída ao longo do texto.

É preciso que se observe que diferenças na organização retórica dos artigos acadêmicos existem uma vez que "cada área e cada problema de pesquisa determinam o modo como a pesquisa será desenvolvida e, como consequência, a configuração final do artigo que relatará a pesquisa" (MottaRoth \& Hendges, 2010:66).

A configuração final dos artigos implica a existência não apenas de seções organizadas de maneiras diferentes, como também de tipos diferentes de artigos, como veremos a seguir.

\subsection{A classificação dos artigos acadêmicos}

Os artigos acadêmicos podem ser classificados em Artigos Teóricos e Artigos Experimentais (Morris, 1966 apud Crookes, 1986; Swales, 2004) e, 
ainda, em Artigos de Revisão (Peterson, 1961 apud Crookes, 1986; MottaRoth, 2001; Swales, 2004).

Os Artigos Teóricos tratam de assuntos e/ou pesquisas que não envolvem a coleta de dados à maneira da pesquisa experimental.

Os Artigos Experimentais, segundo Swales (2004), baseiam-se em estudos sobre dados coletados. Motta-Roth aponta que esses artigos "apresentam fatos referentes à pesquisa experimental sobre um problema específico" (2001:18). Motta-Roth e Hendges (2010:66-67) ampliam essa classificação ao explicar que há diferença entre o Artigo Experimental, que "relata um experimento montado para fins de testagem de determinadas hipóteses" e Artigos Científicos Empíricos, que "não relatam uma pesquisa desenvolvida em um ambiente experimental controlado, mas reportam a observação direta de fenômenos conforme percebidos pela experiência”.

Baseado em suas próprias reflexões e no trabalho de Noguchi (2001), Swales (2004:209) aponta algumas características do Artigo de Revisão: leva informações a uma gama abrangente de pessoas, oferece a oportunidade de refletir sobre o passado bem como sobre eventos futuros e possibilita que o autor do artigo contribua para sua área de estudo. Ainda segundo Swales, esse tipo de artigo costuma apresentar um grande número de referências, divisões em seções cujos títulos são baseados em conteúdo (content-based) e poucas figuras.

Swales (2004:209) observa que Noguchi (2001) divide os Artigos de Revisão em quatro categorias: a) artigos que apresentam uma visão histórica de uma faceta de uma área de estudo; b) artigos que descrevem a situação atual de uma área de estudo; c) artigos que propõem uma teoria; d) artigos que chamam a atenção para alguma questão problemática de uma área de estudo. Swales (2004) prefere definir o Artigo de Revisão como, essencialmente, uma revisão da literatura que normalmente é finalizado por algum tipo de avaliação, por parte do autor.

A reflexão aqui apresentada sobre os diversos tipos de artigos acadêmicos foi de grande importância para a classificação dos artigos que fazem parte do corpus desta pesquisa. Com base nessa reflexão, no corpus pesquisado classificamos Artigo de Revisão aquele que relata o panorama histórico de uma teoria e/ou área de estudo, sem que haja a defesa de uma tese; Artigo Teórico, aquele que defende uma posição/tese em relação ao assunto 
do artigo; Artigo Experimental ${ }^{5}$, aquele que apresenta pesquisa baseada em coleta e análise de dados.

O escritor chama as vozes de diferentes autores para o seu texto, ao construí-lo. O diálogo entre escritor e autor corrobora e, por vezes, debate as idéias presentes no texto, assim como fundamenta o diálogo entre o escritor e a sua comunidade discursiva, conforme veremos a seguir.

\section{As VOZES PRESENTES NO ARTIGO ACADÊMICO}

No processo de construção do texto escrito, o autor estabelece diálogo com uma série de outros autores que, direta ou indiretamente, povoarão seu discurso. Por meio dos movimentos retóricos que constroem o texto, ele estabelece o diálogo com a sua comunidade discursiva estabelecendo vínculos de pertencimento e construindo sua identidade como pesquisadorautor. Nesse processo, a escolha do autor do texto por essa ou aquela forma de incorporar a voz do outro (a escolha, portanto, do tipo de citação) é fundamental no desenvolvimento do conhecimento experto a ser reconhecido pela comunidade acadêmica.

Segundo Murray, o indivíduo, ao apropriar-se de um novo discurso, assume uma nova identidade social - mais uma, observa a autora. Essa identidade implica, por sua vez, "uma nova visão do mundo e das coisas que são importantes nesse mundo" (1998:1). A apropriação do novo discurso funciona como fator de referência do profissional perante sua comunidade discursiva e como elemento facilitador da organização e articulação $^{6}$ de idéias e conhecimentos, de acordo com o discurso da referida comunidade (Freeman, 1991). Essa nova identidade resulta do diálogo do autor do texto com outros autores e de seu posicionamento em relação ao texto que produz. Esta pesquisa está voltada para o posicionamento do autor-sujeito em seu texto escrito - especificamente pela maneira como constrói citações.

5. A pesquisa relatada neste artigo foi executada em 2006. Os artigos acadêmicos que fazem parte do corpus da pesquisa e que apresentam coleta e análise de dados foram classificados como Experimentais, pois a obra de referência à época (Motta-Roth et al, 2001) ainda não incluía a classe dos Artigos Empíricos.

6. "Articulação refere-se à capacidade de distinguir, explicar, e, assim, organizar e criar coerência entre os aspectos da prática [profissional]“ (Freeman, 1991:447). 


\subsection{A citação e a construção do discurso acadêmico}

Fazer referência a autores e a suas obras demonstra conhecimento do trabalho desenvolvido na comunidade acadêmica. Entretanto, isso também está relacionado a uma série de valores e crenças defendidos por essa comunidade. Ivanič (1998) acredita que os autores fazem citações para demonstrar, entre outros aspectos, que passaram por um processo de reflexão ao realizarem suas pesquisas. Ainda segundo a autora, a citação de outros autores é valorizada pela comunidade acadêmica e não citar significa colocar em xeque valores já consolidados.

Segundo Bakhtin (1999), a citação se concretiza na tensão desta com o contexto da obra que a contém. A maneira como a citação será revelada, no texto, dependerá da maneira como a voz do outro é tratada pela comunidade na qual o texto circulará. Quanto maior o caráter de autoridade dessa voz, tanto mais explícita poderá ser a citação. A comunidade acadêmica estabelece regras específicas para a estruturação de citações. Essas regras podem ser flexíveis, mas é preciso levá-las em consideração, uma vez que são legitimadas pela sociedade que as produz e as utiliza - a língua é um fenômeno coletivo, não individual.

Entendemos, então, que citar o discurso do outro é assumir a presença do outro em um texto que pretendo chamar de "meu", é admitir que o meu discurso é, na verdade, um conjunto de vozes que se encontram e se manifestam no "meu texto". É admitir, enfim, que existo a partir do outro e a partir da forma como articulo essa relação. Entretanto, permitir a presença do outro em "meu" texto não implica submissão, passividade, e sim o entendimento de que a construção do conhecimento ocorre justamente em função da tensão entre as diversas vozes que povoam o texto.

Observar o efeito de citações em um texto é observar a maneira como o texto se comporta no momento em que a voz do outro é chamada para esse texto. Hyland (2000) observa que a articulação das vozes presentes no texto é complexa, pois envolve muito mais do que regras de estruturação e organização, uma vez que as diferentes escolhas sobre a forma de estruturar as citações possuem diferentes significados sociais. Por exemplo, Swales (1990), referindo-se especificamente ao discurso científico, estabelece a diferença entre citação integral (na qual o nome do autor citado é um elemento da oração) e citação não-integral (na qual o nome do autor citado aparece entre parênteses, em notas de rodapé etc.). Para Hyland 
(2000), o uso de um tipo de citação, e não de outro pode referir-se à decisão do autor do texto de destacar o autor citado (no caso da citação integral, por exemplo) ou a teoria/pesquisa citada (como, por exemplo, no caso da citação não-integral).

Pesquisas demonstram que no artigo acadêmico a informação precisa ser combinada à interação social. $\mathrm{O}$ autor do texto busca não apenas comunicar os resultados de sua pesquisa, como também convencer o leitor de que seu trabalho é pertinente e importante, de modo a conseguir aceitação por parte da comunidade científica (Hyland, 1999). Hyland (p. 142) indica, ainda, que esse processo de negociação entre o autor e o leitor implica situar o relato da pesquisa em um contexto maior, o que é mais "claramente demonstrado por meio de citações". As citações podem ser categorizadas de diversas maneiras, de acordo com a idéia que pretendem veicular, como veremos a seguir.

\subsection{Formas de categorizar citações}

Ao fazer uma citação, escolhemos um autor em vez de outro (Bavelas, 1978). Citar, portanto, é um ato que está relacionado aos valores e préjulgamentos de quem cita. Bavelas aponta que um dos motivos para que sejam feitas citações em artigos acadêmicos é a própria necessidade de o autor do texto demonstrar à sua comunidade científica que tem conhecimento de obras importantes em sua área de estudo. Essa necessidade pode ser influenciada por pressões sociais, moda, tradição, respeitabilidade acadêmica ou cortesia, e a função da citação pode ser a de conferir àquele que cita credenciais de autor respeitável. De uma maneira ou de outra, a ação de citar será guiada pela percepção do que seja consenso na comunidade científica, de modo que o autor do texto demonstre familiaridade com essa comunidade e com sua área de estudos:

Fazemos algumas citações, pois achamos que nossos colegas consideram aquelas obras importantes e queremos que eles saibam que nós sabemos disso. Essas obras "deveriam" ter tido impacto acadêmico sobre nós, quer tenham tido, ou não (Bavelas, 1978:160) ${ }^{7}$.

7. No original: "We make some citations because we think our colleagues think they are important and we want to show we know that. These works "should" have had a scholarly impact on us, whether or not they actually did" (Bavelas, 1978:160). 
Ainda segundo Bavelas (1978), isso não quer dizer que citamos por razões meramente formais, mas sim que citamos por razões idiossincráticas. Essa também é a percepção de autores como Cronin (1981). Para o referido autor, há uma infinidade de razões que levam um autor a utilizar citações em seu texto. Essas razões muitas vezes não estão relacionadas às convenções que impõem normas para o uso e forma de citações em trabalhos acadêmicos. Além de fatores sociais e psicológicos, Cronin (1981) aponta os seguintes fatores externos que determinam o uso de citações: a percepção do autor sobre o público-alvo; as características e o status do periódico no qual o artigo será publicado; o âmbito, os objetivos e o formato do artigo; o conhecimento e a compreensão do autor sobre a sua área de estudos; a sua habilidade de fazer uso de outras fontes.

A necessidade de provocar impacto sobre o público-alvo merece a atenção de Gilbert (1977), que considera o artigo acadêmico um "instrumento de persuasão" (grifo do autor), uma vez que o autor-pesquisador precisa convencer seus pares de que sua pesquisa é importante. $\mathrm{O}$ autor do texto almeja que os resultados de sua pesquisa sejam reconhecidos como conhecimento científico. Assim, a citação desempenha papel significativo no processo de construção de um artigo acadêmico que se propõe a persuadir: a citação de obras cuja relevância já está aceita e estabelecida na comunidade científica serve como justificativa para as posições tomadas pelo autor do texto que faz a citação, além de tornar clara sua afiliação teórica. Além disso, esse autor pode utilizar a citação para demonstrar que os resultados de seu trabalho, de alguma forma, ampliam o conhecimento advindo das obras citadas.

Cronin (1981) considera a ação de citar algo que só poderá realmente ser detectado e medido por meio de entrevista com aquele que cita - pois só ele pode relatar suas intenções ao utilizar essa ou aquela citação - e que qualquer outra tentativa de estudo de citações permaneceria apenas no campo das conjecturas. Entretanto, Cronin (1981) reconhece que diversas tentativas têm sido realizadas visando ao estabelecimento de tipologias e categorizações que nos ajudem a compreender um pouco mais as razões que levam um autor a fazer citações em seu texto. Cronin observa que as análises procuram chegar a explicações plausíveis para a existência de citações em um dado texto. $\mathrm{O}$ autor destaca esforços como os de Chubin e Moitra (1975) e Moravcsik e Murugesan (1975) para organizar tipologias que auxiliem os estudos sobre citações. Moravcsik e Murugesan (ibid.), ao 
organizarem uma categorização que pudesse auxiliar a análise de citações, enfocam variáveis para indicar a natureza das citações. As perguntas que nortearam a pesquisa relatada pelos referidos autores foram as seguintes:

1) A citação é conceitual (relaciona-se a um conceito ou teoria) ou operacional (relaciona-se a um instrumento ou técnica)?

2) A citação é orgânica (realmente necessária para a compreensão do texto que a cita) ou perfunctória (apenas reconhecimento da existência de uma obra na qual a mesma idéia já tenha sido apresentada)?

3) A citação é evolucionária (o texto que traz a citação parte das bases propostas pela obra citada) ou justaposta (o texto que cita apresenta uma alternativa à obra citada)?

4) A citação é confirmativa (defende que a obra citada está correta) ou negativa (coloca em xeque a obra citada)?

Para Moravcsik e Murugesan (1975), as perguntas 1 e 3 podem revelar algo sobre os objetivos do texto onde se insere a citação, bem como o tipo de conexões que caracterizam o desenvolvimento científico. As perguntas 2 e 4 estão relacionadas à qualidade das citações. Note-se, também, que os autores registraram as ocorrências de citações que não se encaixavam em nenhuma das duas categorias em cada uma das quatro dimensões que compõem a categorização (por exemplo: conceitual ou operacional ou nenhuma das duas). Os autores aplicaram essa categorização a trinta artigos acadêmicos da área da Física, publicados, em inglês, no Physical Review, entre 1968 e 1972. Os resultados mostraram uma maior ocorrência de citações conceituais, orgânicas, evolucionárias e confirmativas.

Conforme o tratamento que os dados recebem, as pesquisas sobre citação podem ser divididas em estudos que: 1) utilizam o número de vezes em que um artigo é citado como parâmetro de qualidade; 2) utilizam o número de vezes em que um artigo é citado para avaliar o impacto da obra sobre a comunidade científica; 3 ) constroem tipologias de diferentes variedades de referências e citações ${ }^{8}$, por meio de uma análise de conteúdo (Gilbert, 1977).

8. Peritz (1983) estabelece que o termo Referência relaciona-se à obra citada (nome do autor e/ou da obra), enquanto que o termo Citação refere-se à menção/comentário/paráfrase da obra no texto que a contém. 
A nossa pesquisa tem por objetivo observar as variedades de citações em dois gêneros do discurso acadêmico. Selecionamos a categorização de Moravcsik e Murugesan (1975) para orientar a observação dessas variedades, por considerarmos que poderá ser aplicada às subáreas de Linguística e Linguística Aplicada, contribuindo para a compreensão sobre a questão da citação em gêneros do discurso acadêmico.

A seguir, veremos a Metodologia adotada em nosso estudo.

\section{Metodologia}

A coleta e análise dos dados desta pesquisa, de caráter qualitativo e interpretativo, ocorreu no próprio contexto de estudo dos participantes. Realizou-se no âmbito do Curso de Pós-Graduação em Estudos Linguísticos da Faculdade de Letras de uma Universidade Federal brasileira e contou com a participação de uma turma de alunos de uma disciplina, durante o primeiro semestre letivo de 2004, com duração de 60h/aula, durante o período de 24/03/2004 a 07/07/2004.

Os participantes são treze alunos voluntários (aqui identificados por pseudônimos), matriculados em uma disciplina do curso de pós-graduação. Foram escolhidos participantes que já tivessem concluído seu curso de graduação. Esse critério precisou ser estipulado, pois as disciplinas do referido curso são abertas a alunos que ainda estejam cursando a graduação. A pesquisa envolveu tanto os alunos mestrandos e doutorandos, como os alunos matriculados em disciplina isolada, ou seja, não inscritos nos Cursos de Mestrado e Doutorado da referida Faculdade. As razões dessa decisão são duas. A primeira é o fato de que a existência de um grupo como o examinado, de caráter heterogêneo, é frequente em cursos de pós-graduação em Letras, no Brasil, o que poderá suscitar reflexões sobre o ensino e a aprendizagem de escrita acadêmica em cursos de pós-graduação. A segunda é o fato de haver a possibilidade de observar a produção de textos escritos de alunos com diferentes níveis de conhecimento experto em escrita acadêmica, algo que poderá ser determinante na maneira como as citações são construídas em seus textos.

Os corpora da pesquisa estão assim divididos:

Corpus 1: nove artigos acadêmicos. Os artigos foram selecionados segundo os seguintes critérios: a) pertencerem às subáreas de Linguística e 
Linguística Aplicada; b) terem sido publicados entre a segunda metade da década de 1990 e 2005. Essas datas de publicação foram assim estabelecidas por uma questão de proximidade do ano em que os trabalhos dos alunos participantes da pesquisa foram produzidos (2004); c) constituírem três exemplares de Artigos Experimentais, três exemplares de Artigos Teóricos e três exemplares de Artigos de Revisão, conforme definições dos referidos tipos de artigo já apresentadas anteriormente neste artigo; d) terem sido publicados em um periódico indexado, classificado Qualis A pela CAPES, no caso, a Revista DELTA. Esses artigos têm as citações neles contidas utilizadas como dados de comparação (Stubbs, 1994) por terem sido escritos por membros expertos da comunidade discursiva e publicados em um periódico legitimado por essa comunidade.

Corpus 2: treze trabalhos finais de disciplina de alunos de pós-graduação. Conforme solicitado pela professora da disciplina, os trabalhos vinculamse ao gênero do discurso acadêmico projeto de pesquisa (de mestrado ou doutorado).

A comparação entre os artigos acadêmicos e os trabalhos finais de disciplina foi julgada pertinente pelos seguintes motivos: a) as convenções que regem a escrita na comunidade acadêmica fazem-se presentes nos gêneros do discurso escolhidos pelos membros dessa comunidade para comunicar os resultados de suas pesquisas; b) o gênero artigo acadêmico é um gênero já legitimado pela comunidade acadêmica como um importante mecanismo de comunicação entre seus membros; c) o trabalho final de disciplina é um gênero do discurso que faz parte do contexto do aluno de cursos de pósgraduação; d) o projeto de pesquisa apresenta organização retórica similar a do gênero artigo acadêmico: Introdução, Revisão da Literatura, Metodologia. A seção Análise e Discussão dos Dados é incluída no caso de o projeto apresentar um estudo piloto; e) as convenções que regem o uso de citações são análogas nos dois gêneros do discurso aqui analisados, uma vez que os dois se realizam no mesmo registro: o acadêmico (cf. Bhatia, 2004).

As aulas foram observadas e os alunos participantes da pesquisa foram entrevistados; entretanto, este artigo traz apenas os dados referentes aos seus textos escritos.

As citações foram mapeadas segundo sua natureza e seus verbos de elocução. Entretanto, neste artigo, serão demonstrados apenas os dados referentes à natureza das citações. $\mathrm{O}$ mapeamento manual e posterior 
análise das citações de ambos os corpora foi realizado conforme se descreve a seguir.

a) Foram utilizados os conceitos de citação integral e citação não integral de Swales (1990), explicados anteriormente, neste artigo.

b) Foi utilizada a categorização de citações adotada por Moravcsik e Murugesan (1975), também já explicitada neste artigo. As categorias são as seguintes:

1 - citação conceitual / operacional / nenhuma das duas;

2 - citação orgânica / perfunctória / nenhuma das duas;

3 - citação evolucionária / justaposta / nenhuma das duas;

4 - citação confirmativa / negativa / nenhuma das duas.

\section{Análise de Dados e Resultados}

Os resultados referentes aos dados extraídos dos dois corpora serão apresentados separadamente, nesta seção.

\subsection{Corpus 1: artigos acadêmicos}

Nas 688 citações analisadas nos nove artigos acadêmicos, os dados demonstram que: a) há um maior número de citações nos artigos teóricos (390) e nos de revisão (208); b) poucas citações são observadas na seção da Metodologia, unidade esta presente apenas nos artigos experimentais analisados; c) as citações apresentam-se em 79,94\% das ocorrências, no seguinte padrão: Citação conceitual (relaciona-se a um conceito ou teoria), orgânica (realmente necessária para a compreensão do texto que faz a citação), evolucionária (o texto que cita parte das bases da obra citada) e confirmativa (defende/atesta que a obra citada está correta). Por outro lado, as citações negativas (que colocam em xeque a obra citada) e as citações justapostas (o texto que cita apresenta uma alternativa à obra citada) ocorrem poucas vezes $-8,57 \%$ e $1,16 \%$, respectivamente. Note-se que nas citações negativas observadas nos artigos acadêmicos, o escritor usa a própria voz para colocar em xeque a obra citada. As citações negativas e justapostas 
observadas estão presentes apenas em artigos que, desde o seu início, têm como proposta discutir uma dada teoria, e apresentar alternativas a essa teoria. De modo geral, nos nove artigos analisados, as citações são construídas para corroborar as idéias de quem cita; d) as citações perfunctórias (apenas reconhecimento da existência de uma dada obra) e as operacionais (relacionadas a um instrumento ou técnica) ocorrem em menor número $(5,08 \%$ e $1,30 \%$, respectivamente) nos nove artigos analisados; e) as citações integrais são a maioria nos artigos teóricos $(76,15 \%)$ e experimentais $(53,33 \%)$; nos artigos de revisão ocorrem em um número um pouco menor $(47,11 \%)$ em relação às não-integrais $(50,96 \%)$. Lembremos que a citação integral, redigida no corpo do texto, destaca, em um primeiro momento, o autor citado, e não a obra. Isso pode significar que os escritores valorizam $\mathrm{o}$ indivíduo autor da obra, e percebem em primeiro lugar esse indivíduo, e não a sua obra, como a autoridade da área de conhecimento.

\subsection{Corpus 2: trabalhos finais de disciplina}

Quanto à configuração, os trabalhos finais de disciplina aqui assumiram a forma de Projetos de Pesquisa (ou pré-projetos, no caso dos trabalhos dos alunos ainda não matriculados como mestrandos ou doutorandos).

A estrutura das 456 citações contidas nos trabalhos finais de disciplina dos alunos participantes da pesquisa não é muito diferente do que é observado nos artigos acadêmicos. Os números demonstram que: a) apesar de pertencerem a uma turma heterogênea, a maioria das citações observadas nos trabalhos finais $(95,61 \%)$ apresenta-se no padrão Citação conceitual, orgânica, evolucionária e afirmativa; entretanto, comparativamente, os doutorandos utilizam mais citações (167) que os demais alunos (80), talvez em função de sua maior experiência com gêneros do discurso acadêmico, e consequentemente, de maior conhecimento da estrutura e função das citações; b) as citações negativas apresentam baixa ocorrência $(1,31 \%)$ e, quando ocorrem, colocam em xeque a obra citada por meio da voz de outros autores, e não da voz de quem cita. Os alunos relataram não estarem prontos, naquele momento de sua vida acadêmica, para discordar da voz da autoridade utilizando suas próprias vozes; $c$ ) as citações perfunctórias e as operacionais ocorrem em menor número $(3,07 \%)$ e há pouca, ou nenhuma, ocorrência de citações na seção da Metodologia; d) as citações integrais são 
a maioria (80,48\%), o que, como já mencionado, coloca em primeiro plano o indivíduo autor citado, e não a sua obra.

Por outro lado, duas diferenças podem ser observadas, em relação aos artigos publicados: a) as citações justapostas não ocorrem nos trabalhos finais de disciplina, o que se explicaria pelo fato de que esse tipo de citação implica experiência no trato com o conhecimento da área de estudo em questão, de maneira que este possa fundamentar propostas de mudanças naquilo que a comunidade acadêmica considera tradição/autoridade dessa área de estudo; b) há uma menor variedade de padrões de citação nos trabalhos finais de disciplina, o que pode estar relacionado à pouca experiência dos alunos com o discurso acadêmico. Por exemplo, os alunos parecem desconhecer que a seção da Metodologia também pode conter citações, o que faz com que citações operacionais sejam raras em seus trabalhos. A seguir, detalharemos um pouco mais essa análise comparativa dos dois gêneros estudados.

\subsection{Análise comparativa das citações presentes nos artigos acadêmicos e nos trabalbos finais de disciplina}

Ivanič (1998) explica que não apenas temos múltiplas identidades, dependendo do papel social que assumimos em determinadas situações, como também assumimos identidades diferentes em um mesmo texto escrito. Há momentos, em um artigo acadêmico, em que as vozes de outros autores são chamadas com mais freqüência, como na seção da Revisão da Literatura, por exemplo. Swales (2004) observa que nas seções iniciais (Introdução, Revisão da Literatura) as obras de outros têm papel principal e a pesquisa que as cita assume um papel secundário - deixando o foco para a palavra da autoridade, da tradição da comunidade discursiva. Na seção de Discussão, por outro lado, a pesquisa que cita recebe o foco principal, uma vez que são os seus achados que serão relatados e discutidos. Nesse momento, as obras de outros autores assumem uma posição secundária, uma vez que se fazem presentes para corroborar, comparar e, mesmo, contradizer as idéias do pesquisador que as cita. As observações de Ivanič (1998) e Swales (2004) são evidenciadas de maneira especialmente clara nos artigos experimentais analisados nesta pesquisa, em que as seções da Análise e Discussão dos Dados estão mais nitidamente definidas. No Artigo Experimental 1, por exemplo, nas seções denominadas "Introdução", "Perspectiva Teórica" e "Método Empregado na Investigação" ocorrem 37 
citações, enquanto que nas duas últimas seções, denominadas "Resultados e Discussão" e "Considerações Finais" ocorrem 7 citações. Não foi possível observar essa situação nos trabalhos finais dos participantes da pesquisa, pois são projetos de pesquisas que ainda serão executados e que, portanto, ainda não apresentam as seções de Análise e Conclusão.

Apenas um dos nove artigos acadêmicos - um Artigo de Revisão -, e apenas um dos trabalhos finais de disciplina não apresentaram citações em sua seção introdutória. Isso corrobora os achados de Myers (1990) em sua análise de artigos acadêmicos. $\mathrm{O}$ referido autor observou que as citações começam a ocorrer desde o início do texto, justificando essa ocorrência como uma maneira de o autor situar imediatamente seu artigo no contexto da literatura da área de estudos na qual esteja inserido.

Veremos, a seguir, alguns exemplos dos padrões de citação encontrados.

Como mencionado anteriormente, a maioria $(79,94 \%)$ das 688 citações dos artigos acadêmicos analisados apresenta o padrão Citação conceitual, orgânica, evolucionária, confirmativa. Esse padrão está estruturado em modo declarativo afirmativo. O Exemplo $[1]$ ilustra essa ocorrência:

[1] Artigo Experimental 2: O autor analisa fenômenos convencionalmente ditos suprassegmentais (hesitações, gagueiras, pausas) que "[...] incidem sobre o processo do dizer e da constituição da subjetividade no exercício oral da linguagem" (Souza, 2000a: 02).

Esse padrão também é majoritário $(95,61 \%)$ nas 456 citações contidas nos trabalhos finais de disciplina (corpus 2) realizados pelos participantes da pesquisa, conforme ilustra o exemplo a seguir:

[2] Trabalho de Bruna: Em relação à fonologia, os aprendizes de uma segunda língua, como afirma Leather (1999:26), fazem uso dos sons de sua língua materna para desenvolver problemas fonológicos que encontram durante a sua aquisição da L2.

Há um número bastante reduzido de citações negativas. Esse tipo de citação, que ocorre no padrão Citação conceitual, orgânica, evolucionária e negativa, é observado em $8,57 \%$ dos artigos acadêmicos e em 1,31\% dos trabalhos finais. Esse padrão está estruturado conforme veremos a seguir:

9. Os exemplos não foram redigidos em itálico ou entre aspas para preservar essas marcas exatamente da maneira como foram utilizadas pelo escritor. 
[3] Artigo Teórico 1: Seu conceito de superestrutura, desse modo, como o próprio autor afirma (van Dijk, 1990:78), ficou incompleto.

[4] Artigo Teórico 1: A visão de Adam, com conceitos complexos e pouco delimitáveis, dificulta a aplicação de um suporte teórico de processamento cognitivo.

[5] Artigo Teórico 1: Dado o exposto até agora, pode-se presumir que o esquema narrativo de van Dijk (1978) não é uma superestrutura, mas um esquema textual básico para a formação de algumas superestruturas.

Nos exemplos acima, é possível observar que a polaridade negativa (Halliday, 2004) não se dá apenas por meio do uso do adjunto de polaridade NÃO - observado no exemplo [5]: Dado o exposto até agora [...] nãa é uma superestrutura. O processo também realiza a noção semântica de polaridade (afirmativo/negativo), como no caso do exemplo [4]: A visão de Adam [...] dificulta [...]. No caso do exemplo [3], temos a presença de um atributo: Seu conceito de superestrutura [...] ficou incompleto. Observamos, ainda, que no exemplo [3], o escritor lança mão da voz do próprio autor citado para colocar a obra deste em xeque. Por outro lado, nos exemplos [4] e [5] o escritor utiliza a sua própria voz para discordar das idéias citadas.

Nos exemplos [6] a [8], a seguir, pode-se perceber a utilização de citações negativas por alunos de diferentes níveis de experiência em escrita acadêmica (alunos matriculados em disciplina isolada, mestrandos e doutorandos).

[06] Trabalho de Sarah (matriculada em disciplina isolada): Diferente desses teóricos está Kenneth Goodman (1994) que acredita que a linguagem é influenciada pelo contexto social e pelas características pragmáticas.

[07] Trabalho de Arthur (mestrando): Em contraposição a esses teóricos, Widdowson (1991) afirma que a sala de aula constitui-se uma ilusão e seu posicionamento teórico vem para corroborar minha percepção, como aprendiz e docente, do que seja um ambiente de aprendizagem no que se refere às limitações que envolvem suas interações orais.

[08] Trabalho de Mateus (doutorando): No entanto, pesquisadores têm argumentado que os aprendizes são, normalmente, capazes de superar seus problemas de comunicação sem, necessariamente, a negociação de sentido, e que essa perspectiva teórica não conseguiu fornecer evidências convincentes de que a negociação de sentido leve à aquisição de segunda língua (Ellis, 1994, Swain, 2000).

Sarah, matriculada em disciplina isolada, constrói uma citação que só pode ser compreendida como negativa, se observarmos o restante de seu trabalho, seus objetivos e justificativa. Essa participante da pesquisa 
concluiu o curso de graduação em 1986. Sarah diz não ter tido a oportunidade de estudar a escrita acadêmica na graduação, entretanto, constrói uma citação negativa de maneira tão sutil como algumas encontradas nos artigos acadêmicos.

As demais ocorrências de citações negativas nos trabalhos dos participantes da pesquisa são utilizadas para dar suporte a uma opinião do participante (o escritor) que, por ter idéias que vão de encontro a uma teoria já estabelecida (a autoridade), lança mão de outras teorias, igualmente representativas da autoridade da comunidade acadêmica, para corroborar suas opiniões.

Arthur, aluno do curso de mestrado, ainda não havia feito disciplina do Curso de Pós-graduação antes de nele ingressar. Concluiu o curso de graduação em 2003 e nele afirmou ter tido a oportunidade de estudar algo sobre citações. Mateus, doutorando, possui certa experiência em escrita acadêmica. Não estudou as características e regras de construção de citações durante a graduação, mas possui a experiência dos textos desenvolvidos durante o curso de mestrado.

O número de citações perfunctórias (que apenas reconhecem a existência de uma obra na qual a mesma idéia já tenha sido apresentada) encontrado nesta pesquisa é pequeno (5,08\% nos artigos acadêmicos), não corroborando análises de citações que atestam ser esse tipo de citação bastante comum (cf. Moravcsik \& Murugesan, 1975; Chubin \& Moitra, 1975). No Exemplo [9], vemos uma citação perfunctória encontrada na análise dos dados desta pesquisa.

[09] Artigo Experimental 1: Nesse sentido, os estudos empíricos baseados em corpora têm-se tornado cada vez mais variados, explorando desde o conceito mudança lingüística (descrito por Catford [1965] como desvio da correspondência formal) a investigações de características universais da linguagem da tradução e seu aspecto ideológico.

Nesta pesquisa, as citações são classificadas como neutras "no momento em que aquele que cita não indica claramente a sua atitude em relação à informação/opinião do autor citado" (Thompson \& Yiyun, 1991:372). Thompson (1996) cita um aspecto importante que é evidenciado no corpus 1 desta pesquisa: às vezes, a mudança de um relato positivo para um neutro pode indicar que logo à frente o escritor discordará do autor citado. 
Isso pode ser observado nos exemplos [10] e [11], retirados de um mesmo artigo, e que ocorrem em seqüência:

[10] Artigo Teórico 1: Para explicar o racismo (van Dijk, 1991), por exemplo, o autor utilizava um esquema em forma de matriz (v. fig. 5) que apresenta uma oposição entre instâncias da interação e da cognição e uma gradação dos processos dentro destas instâncias (micro e macro).

[11] Artigo Teórico 1: A visão de Adam, com conceitos complexos e pouco delimitáveis, como o de interdiscurso, dificulta a aplicação de um suporte teórico de processamento cognitivo.

No exemplo [10], temos um padrão de citação que ocorre em 3,92\% das 688 citações mapeadas nos artigos e não ocorre nos trabalhos finais de disciplina: o padrão Citação conceitual, orgânica, evolucionária e "neutra" (assim classificada por ser não-confirmativa e não-negativa). Logo em seguida, no exemplo [11], temos um padrão em que a polaridade negativa é concretizada por meio de um processo (dificultar), caso já discutido na demonstração do mesmo exemplo, numerado anteriormente como [4].

O padrão de Citação conceitual, orgânica, justaposta e confirmativa ocorre apenas em um artigo teórico, da seguinte maneira: no referido artigo, há treze citações que não apresentam polaridade negativa, mas que são refutadas após a $13^{a}$ citação. Essas citações poderiam ser classificadas como negativas, dado o contexto, mas não há elemento em sua estrutura interna que fundamente tal classificação. Além disso, essas citações não estão presentes no texto apenas para colocar em xeque a obra citada, mas para fundamentar as idéias do escritor, que são uma alternativa para as teorias por ele refutadas.

Abaixo, veremos a primeira citação dessa seqüência (Exemplo [12]), a última citação (Exemplo [13]), e o comentário do escritor na seqüência do texto, que aponta para as considerações que fará, logo em seguida, e que serão justapostas ao que foi dito (Exemplo [14]):

[12] Artigo Teórico 3: Tomemos como exemplo o trabalho de Ducrot (1984) sobre polifonia (que não é um dos mais radicais nesse campo).

[13] Artigo Teórico 3: Diz ainda: "não podemos interpretar um enunciado se não sabemos a qual gênero relacioná-lo” (1998:75).

[14] Artigo Teórico 3: Maingueneau fala do gênero como uma atividade mais ou menos ritualizada. Diz ainda: "não podemos interpretar um enunciado se não sabemos a qual gênero relacioná-lo” (1998:75). Mas haveria uma forma pronta para cada tipo 
de necessidade enunciativa cotidiana? [...] Ao ver o gênero como o que é cristalizado (disponível no interdiscurso ou como dispositivo do arquivo), perde-se de vista toda uma gama de textos que não apresentam identidade fixa, que não sendo exemplares de um gênero, ocorrem simplesmente como enunciação construída sobre (e sobre a qual incidem) várias outras. [...] Mais que isso, eu diria que é possível se pensar um enunciativismo "fraco" [...].

Citações operacionais ocorrem em 1,31\% das citações dos nove artigos acadêmicos. Observa-se a presença dessas citações em 3,07\% dos trabalhos finais de disciplina. Como é de se esperar, por se tratar de citações que se relacionam a um instrumento ou técnica, são observadas nas seções que descrevem a metodologia de pesquisa, como veremos a seguir, em alguns exemplos:

[15] Artigo Experimental 2: Tais entrevistas foram realizadas de acordo com a metodologia da Teoria da variação Lingüística (Labov 1972, 1994).

[16] Trabalho de Luana: Além de perguntar diretamente para o professor este item, também haverá uma observação não-participativa, na qual a pesquisadora "participa sem executar tarefas diretamente” (Larsen-Freeman e Long, 1991, p. 16).

As citações operacionais têm baixa ocorrência, mesmo nos artigos experimentais. Swales (2004) observa que a baixa ocorrência de citações na seção de Metodologia, em alguns artigos acadêmicos, pode estar relacionada à opção do escritor pela descrição detalhada dos procedimentos metodológicos - e essa descrição de procedimentos foi observada nos artigos aqui analisados. Swales explica que o escritor opta por um maior número de citações quando há pouco tempo ou espaço para descrições. Por exemplo, o escritor nomeia um instrumento de pesquisa e cita um autor que seja referência para a explicitação desse instrumento, sem deter-se em explicações sobre o mesmo. É o caso da citação apresentada no Exemplo [15], acima.

Nos dados analisados neta pesquisa, as citações, em sua maioria, colocam a pessoa do autor citado em primeiro lugar, e a sua obra, em segundo, ao serem redigidas como citações integrais. Parece-nos que a autoridadeque aqui é entendida como a tradição, a literatura produzida já legitimada pela comunidade acadêmica - é a pessoa. Nos nove artigos foram mapeadas 443 citações integrais e 240 não-integrais. 
Nos trabalhos finais dos participantes, foram mapeadas 367 citações integrais e 89 não-integrais. $\mathrm{O}$ uso de citações não-integrais, segundo Hyland (1999), pode indicar a tentativa do autor do texto de manter uma postura mais objetiva em relação aos fatos, já que suprimir o agente pode diminuir a influência de valores e ideologias que poderiam comprometer o relato dos fatos e todo o processo empírico de investigação da realidade. Veremos, a seguir, exemplos de citações integrais presentes nos artigos e nos trabalhos (Exemplos [18] e [19], respectivamente) e exemplos de citações não-integrais observadas nos artigos e nos trabalhos (Exemplos [20] e [21], respectivamente).

[18] Artigo Experimental 1: Outrossim, a utilização de corpora para os Estudos da tradução também é valorizada por Tymoczko (1998) ao afirmar que essa nova abordagem é importante para a sustentação e desenvolvimento da disciplina neste século.

[19] Trabalho de Mateus: Como ressaltam Brown e Yule (1983), o termo 'análise do discurso' tem sido usado com uma vasta abrangência de significados que cobrem uma ampla extensão de atividades.

[20] Artigo de Revisão 2: Isso talvez aconteça, porque, em primeiro lugar, existe um mito de monolingüismo no país (Cf. Bortoni, 1984, Cavalcanti, 1996a, Bagno, 1999).

[21] Trabalho de Regina: O aluno é agente no processo de formação de LE (ALMEIDA FILHO, J. C. P. - 1993:42).

Como o artigo acadêmico é um dos mais prestigiados gêneros do discurso na comunidade acadêmica, não causa surpresa que, na universidade, a redação de trabalhos acadêmicos com estrutura similar obedeça às convenções que regem a construção de artigos. A organização retórica dos pré-projetos de pesquisa, que são os trabalhos finais de disciplina aqui analisados, apresenta semelhanças com a dos artigos acadêmicos, especialmente os Artigos Experimentais. A organização dos trabalhos que têm por objetivo apresentar uma revisão teórica assemelha-se àquela dos Artigos Teóricos e de Revisão, o que torna mais fácil ver esses exemplares de trabalhos acadêmicos e os artigos acadêmicos como gêneros passíveis de comparação.

Consideramos que essa primeira categorização contribui significativamente para a compreensão do uso das citações nos gêneros analisados, uma vez que por meio dela é possível não apenas observar os padrões em que as citações são apresentadas em textos escritos por membros expertos e 
membros novatos da comunidade acadêmica, como também refletir sobre as implicações da escolha de tais padrões.

\section{Discussão dos DAdos E CoNSIDERAÇões FINAIS}

De modo geral, o papel da citação, nos corpora desta pesquisa, é o de corroborar e fundamentar a idéia/informação do escritor de maneira positiva, de modo a evitar o confronto com a autoridade - com o autor citado. Assim, o padrão de Citação conceitual, orgânica, evolucionária e confirmativa ocorre majoritariamente, tanto nos artigos acadêmicos como nos trabalhos finais de disciplina. Os membros expertos articulam suas escolhas léxicogramaticais de modo a dar ao seu texto um tom de maior neutralidade ${ }^{10}$, talvez em uma tentativa de manter a afirmação o mais distante possível da subjetividade. Os novatos, por sua vez, ficam um pouco distantes dessa neutralidade. Os corpora desta pesquisa revelam que quanto maior é o conhecimento experto de quem escreve, tanto maior é a tendência a lançar mão de recursos que busquem a neutralidade e tanto maior é a variedade de padrões de citações utilizados. Quando há citações negativas, observa-se que os membros expertos usam a própria voz para colocar a obra citada em xeque. Os membros novatos, por sua vez, utilizam a voz de outros autores para refutar idéias presentes em seus textos.

O grande número de citações conceituais, orgânicas, evolucionárias e confirmativas presentes nos corpora aqui analisados corrobora os resultados de análises de artigos acadêmicos realizadas por diversos pesquisadores: Moravecsik e Murugesan (1975) e Chubin e Moitra (1975), na área de Física; Frost (1979), na área de Literatura em língua alemã. White (2004) cita diversas pesquisas que demonstram a mesma situação.

Nesta pesquisa, a baixa ocorrência de citações negativas e justapostas é uma tendência que precisa ser levada em consideração ao refletirmos sobre o papel da citação na comunidade acadêmica dos profissionais das subáreas de Linguística e Linguística Aplicada. Mais estudos precisam ser realizados para que observemos como essa comunidade discursiva utiliza as citações em seus artigos.

10. Lembremos que "neutralidade", neste artigo, é a terminologia usada para fazer referência ao fato de o escritor (quem cita) não evidenciar se sua atitude em relação às informações relatadas em seu texto é negativa ou positiva. 
Não podemos esquecer, ainda, a questão apontada por Moravcsik e Murugesan (1975), no final de seu artigo: se o número de citações justapostas (que apresentam uma alternativa à obra citada) presentes em um dado grupo de artigos é reduzido, a área de estudo em que esses artigos estão inseridos pode ser caracterizada em relação à atividade científica, mas talvez não quanto ao progresso científico, uma vez que é a citação justaposta que traz o conhecimento novo para a área de estudo em questão. Os autores, entretanto, observam que os membros da comunidade discursiva nem sempre concordam quanto ao que deva ser classificado como atividade ou progresso, tornando essa classificação problemática. Acrescentamos, ainda, que o número de citações justapostas, bem como as negativas, presentes nos artigos pode estar relacionado a questões culturais e à maneira como a comunidade discursiva que produz esses artigos se relaciona com a autoridade/obra citada e à maneira como organiza a produção e veiculação de conhecimento.

Os membros novatos de uma dada comunidade discursiva tendem a seguir as convenções estabelecidas pela comunidade ao construir os seus textos escritos (Swales, 1990). Isso ocorre porque esses textos serão associados aos gêneros do discurso que a comunidade utiliza para a comunicação entre seus membros. Não obedecer às convenções significa romper com tradições legitimadas e já estabelecidas como verdades pela comunidade. É possível quebrá-las, colocá-las em xeque, mas é preciso que antes, o membro que as quebra seja reconhecido e respeitado em sua comunidade discursiva, caso contrário, é possível que não seja ouvido por seus pares (Swales, 1990).

Conforme explicitado no início deste artigo, Bhatia (2004) observa que, para que o profissional possa apropriar-se de um dado gênero do discurso, é preciso que tenha conhecimento do funcionamento desse gênero em sua comunidade discursiva. Esse conhecimento, construído em interações nessa comunidade, vai permitir que novos exemplares do gênero sejam produzidos.

Cremos que precisam ser realizados mais estudos que observem os diferentes perfis do continuum novato-experto, estudos esses que possam, por exemplo, proporcionar fundamentação para as disciplinas que venham a abordar a escrita acadêmica de maneira sistematizada. Disciplinas específicas sobre escrita acadêmica seriam muito úteis na construção do conhecimento experto profissional. Os cursos de graduação e pós-graduação poderiam 
inclú́-las em seus programas. Disciplinas sobre escrita acadêmica baseadas na abordagem de gêneros do discurso poderiam auxiliar o aluno a compreender como os textos escritos são construídos, produzidos e legitimados em sua comunidade discursiva. A análise de citações, que poderia fazer parte das discussões ocorridas nessas disciplinas, precisa ter como elemento norteador o fato de as citações estarem presentes em gêneros do discurso amplamente utilizados na comunidade acadêmica. As características específicas desses gêneros e as relações sociais envolvidas na sua produção e utilização acabam por definir o papel das citações presentes nos diversos gêneros do discurso.

Apenas quatro alunos participantes desta pesquisa afirmaram ter estudado algo sobre escrita acadêmica e/ou citação em seus cursos de graduação. Consideramos que é preciso que, ainda no curso de graduação, os alunos tenham contato com assuntos que envolvam a questão da autoria de maneira mais aprofundada. A construção de citações envolve muito mais do que regras de estruturação: envolve o diálogo com outros autores, que trazem suas vozes para os textos de quem cita e para eles contribuem, propiciando o acesso à comunidade discursiva, o diálogo com os outros membros dessa comunidade e a participação na produção do conhecimento.

Recebido em setembro de 2010 Aprovado em maio de 2011 (versão revisada)

E-mails: tmacedo25@yahoo.com.br adriana.pagano@pq.cnpq.br

\section{REFERÊNCIAS BIBLIOGRÁFICAS}

Bakhtin, M. M. (Volochinov). 1999. Marxismo e filosofia da linguagem: problemas fundamentais do método sociológico na ciência da linguagem. Tradução de Michel Lahud e Yara Frateschi Vieira; com a colaboração de Lúcia Teixeira Wisnik e Carlos Henrique D. Chagas Cruz. $9^{a}$ ed. São Paulo: Hucitec.

Bavelas, J. B. 1978. The social psychology of citations. Canadian Psychological Review, v. 19, n. 2, p. 158-163, abril.

BhATIA, V. 2004. Worlds of written discourse: a genre-based view. London: Continuum. 
Chubin, D. E. \& S. D. Moitra. 1975. Content analysis of references: adjunct or alternative to citation counting? Social Studies of Science, v. 5, p. 423-441.

Cronin, B. 1981. The need for a theory of citing. Journal of Documentation, v. 37 , n. 1 , p. 16-24, mar.

FreEMAN, D. 1991. To make the tacit explicit: teacher education, emerging discourse, and conceptions of teaching. Teacher \& Teacher Education, Great Britain, v. 7, n. 5/6, p. 439-454.

Frost, C. O. 1979. The use of citations in literary research: a preliminary classification of citation functions. Library Quarterly, v. 49, n. 4, p. 399-414.

Gilbert, G. N. 1977. Referencing as persuasion. Social Studies of Science, v. 7, p. $113-122$

Halliday, M. A. K. 2004. An introduction to functional grammar. ed. rev. London: Arnold.

Hill, S. S.; Soppelsa, B. F.; West, G. K. 1982. Teaching ESL students to read and write experimental-research papers. TESOL Quarterly, v. 16, n. 3, p. 333-347 apud МоттA-Roth, D. (Org.). 2001. Redação acadêmica: princípios básicos. Santa Maria: Universidade Federal de Santa Maria, Imprensa Universitária.

Hyland, K. 1999. Academic attribution: citation and the construction of disciplinary knowledge. Applied Linguistics, v. 20, n. 3, p. 341-367. .2000. Disciplinary discourses: social interactions in academic writing. Singapore: Longman/Pearson Education.

IVANič, R. 1998. Writing and identity: the discoursal construction of identity in academic writing. Amsterdam: John Benjamins Publishing Company.

KREss, G. 1994. Learning to write. 2 ed. Great Britain: Routledge.

MACEDO, T. S. 2006. A citação como recurso de afiliação acadêmica. $211 \mathrm{f}$. Tese (Doutorado em Estudos Lingüísticos) - Faculdade de Letras, Universidade Federal de Minas Gerais, Belo Horizonte.

Moravcsik, M. J.; Murugesan. P. 1975. Some results on the function and quality of citations. Social Studies of Science, v. 5, p. 86-92.

Morris, J. E. 1966. Principles of scientific and technical writing. New York: McGraw-Hill apud Crookes, G. 1986. Towards a validated analysis of scientific text structure. Applied Linguistics, v. 7, n. 1, p. 57-70.

MоттA-Roth, D. (Org.). 2001. Redação acadêmica: princípios básicos. Santa Maria: Universidade Federal de Santa Maria, Imprensa Universitária. 
; Hendges, G. R. 2010. Produção textual na universidade. São Paulo: Parábola Editorial.

MurRay, H. 1998. The development of professional discourse and language awareness in EFL teacher training. (Originalmente publicado em IATEFL Teacher Trainers SIG Newsletter. Disponível em <http://www.aal.unibe. ch/englisch/PDandLA.pdf > . Acesso em 05 maio 2002.

Mustafa, Z. 1995. The effect of genre awareness on linguistic transfer. English for Specific Purposes, v. 14, n. 3, p. 247-256.

Myers, G. 1990. Writing Biology: texts in the social construction of scientific knowledge. Wisconsin: The University of Wisconsin Press.

Noguchi, J. T. 2001. The science review article: an opportune genre in the construction of science. Tese de doutorado. Universidade de Birmingham, UK.

Peritz, B. C. 1983. A classification of citation roles for the social sciences and related fields. Scientometrics, v. 5, p. 302-312.

Peterson, M. S. 1961. Scientific thinking and scientific writing. New York: Rheinhold apud Crookes, G. 1986. Towards a validated analysis of scientific text structure. Applied Linguistics, v. 7, n. 1, p. 57-70.

PueYo, I. G. 2001. Technical metaphor and the creation of field. The ESPecialist, São Paulo, v. 22, n. 2, p. 191-218.

StubBs, M. 1994. Grammar, text, and ideology: computer-assisted methods in the linguistics of representation. Applied Linguistics, v. 15, n. 2, p. 201-222.

Swales, J. M. 1986. Citation analysis and discourse analysis. Applied Linguistics, v. 7, n. 1, p. 39-56.

. 1987. Utilizing the literatures in teaching the research paper. TESOL Quarterly, v. 21, n. 1, p. 41-68.

. 1990. Genre analysis: English in academic and research settings.

Cambridge: Cambridge University Press.

. 1993. Genre and engagement. Revue Belge de Philologie et d'Histoire, v. 71, n. 3, p. 687-689.

1998. Other floors, other voices: a textography of a small university

building. Mahwah, N.J.: Lawrence Erlbaum Associates, Publishers. . 2004. Research genres: exploration and applications. Cambridge: Cambridge University Press.

. \& C. B. FEAK. 1994. Academic writing for graduate students: a course for nonnative speakers of English. USA: University of Michigan Press. 
Thompson, G. 1996. Voices in the text: discourse perspectives on language reports. Applied Linguistics, v. 17, n. 4, p. 501-529.

. \& Y. YIYUN. 1991. Evaluation in the reporting verbs used in academic papers. Applied Linguistics, v. 12, n. 4, p. 365-381.

White, H. D. 2004. Citation analysis and discourse analysis revisited. Applied Linguistics, v. 25, n. 1, p. 89-116. 